This is a pre-peer reviewed version of the following article: Singh, S. P.,

Singh, J., Stallings, J., Burgess, G. and Saha, K. (2010), Measurement and

analysis of temperature and pressure in high altitude air shipments.

Packaging Technology and Science, 23: 35-46. doi: 10.1002/pts.877, which has

been published in final form at http://onlinelibrary.wiley.com/doi/10.1002/pts.877/abstract

\title{
Measurement and Analysis of Temperature and Pressure in High Altitude Air Shipments
}

\author{
By S. P. Singh, ${ }^{1}$ J. Singh, ${ }^{2}$ J. Stallings, ${ }^{1}$ G. Burgess ${ }^{1}$ and K. Saha ${ }^{1}$ \\ ${ }^{1}$ School of Packaging, Michigan State University, East Lansing, MI \\ ${ }^{2}$ Industrial Technology, Cal Poly State University, San Luis Obispo, CA
}

\begin{abstract}
SUMMARY
This study was performed (at the request of the FAA) to measure temperature and pressure conditions observed by standard packages in the FedEx 'Next Day Air' network and the environmental conditions of passenger aircrafts. To measure the single parcel environment, two destinations known to be served by non-pressurized feeder and pressurized aircrafts in the USA, San Luis Obispo, California, and Twin Falls, Idaho, were used to represent higher altitude paths. Test packages $(0.30 \times 0.30 \times 0.30 \mathrm{~m})$ containing one MadgeTech PRTemp110 recorder were shipped Priority Overnight by FedEx from East Lansing, Michigan. For 6 weeks, two test packages were shipped to each destination. To measure the passenger aircraft environment, test packages $(0.14 \times 0.11 \times 0.06 \mathrm{~m})$ were both carried in the passenger cabin and checked with luggage. Results show temperature ranges, pressure drop rates, and maximum altitudes observed from 52 flights (17 feeder aircrafts) in the FedEx environment and from eight commercial passenger flights. This study compares these results with the ASTM D6653-01 test procedure with respect to suggested test pressure, pressure change rate, temperature, and test duration.
\end{abstract}

KEY WORDS: feeder aircraft; package shipment; temperature; pressure; altitude

\section{INTRODUCTION}

Packaged goods are often moved to and from all populated areas. The continuous increase of shipped packaged goods has led to more efficient methods and models of transportation. To decrease the costs and time associated with package distribution, many systems consist of complex networks and throughout these distribution systems, packaged goods are subjected to a variety of physical and environmental hazards. Today, package carrier companies utilize all possible modes of transportation and packaging must be designed to protect goods throughout all hazards associated.

For the past 6 years, Michigan State University's School of Packaging has been involved in studies to determine the effects of simultaneous vibration and low pressure on package integrity. These projects, funded by the Federal Aviation Administration and conducted by the Consortium of Distribution Packaging Research are aimed at identifying problems with existing packages and developing new test methods that can reduce the number of leaks in air-shipments. The initial studies were done on liquid hazardous material packaging. ${ }^{1}$ The studies were the result of increased number of leaks and package failures of dangerous goods in commercial and cargo aircraft in recent years. ${ }^{2,3}$ Based on these studies, Singh et al., have developed new test methods that use simultaneous low pressure and random vibration to simulate high-altitude shipping environments. ${ }^{4}$ In addition, pictorial markings 
intended to identify inadequate packages have also been developed. ${ }^{5}$ Yet another study showed that packages currently being used for shipments of liquid pharmaceuticals that are tested to existing ASTM and ISO shipping tests were often inadequate, and could result in a significant number of leakers. ${ }^{6}$ Testing under combined vibration and pressure was recommended as necessary to insure integrity. The vibration test recommended was a combined truck/air spectrum created using the highest Power Density levels for each frequency listed for the individual truck and air vibration spectrums described in ASTM D4169. The pressure inside the vacuum chamber was recommended to be reduced in accordance with ASTM D6653-01 to simulate the conditions in an un-pressurized cargo compartment at $4267 \mathrm{~m}$.

This research studied the temperature and pressure trends that a package might get exposed to for FedEx's 'Next Day Air' shipping environment. In the continental USA, FedEx Express provides a range of shipping services for delivery of small packages up to 150 pounds $(68 \mathrm{~kg})$ and delivery is guaranteed in one to three business days. ${ }^{7}$ FedEx Express' most popular service in the USA is the 'FedEx Priority Overnight'. In this service, packages or envelopes can be shipped and delivered by 10:30 a.m. on the next business day. ${ }^{7}$ To achieve this, FedEx Express uses the "Hub and Spoke" system to deliver packages. FedEx Express' 664 local operating Facilities, located all around the USA, serve as the 'spokes'. ${ }^{8}$ Of the 5 air express hubs, the FedEx Express Super Hub is strategically located in Memphis, Tennessee. ${ }^{8}$ Other continual US hubs are located in Fort Worth, Texas, Indianapolis, Indiana, Newark, New Jersey, and Oakland, California. As packages are moved though this network of locations and though a variety of transportation vehicles (Figure 1), packages are subjected to a series of hazards such as drops, impacts, crushing forces and climatic conditions before it reaches the consumer.

If the package's destination is not immediately served by a major airport or is located in a remote area, it is introduced into a 'feeder' aircraft network. The cargo area is not pressurized in many feeder aircrafts and when necessary, these aircraft fly at altitudes that affect the environmental conditions in the cargo area. When exposed to these conditions, products and/or packages may be unfavorably affected by the changes in pressure and temperature.

In 2001, the United Parcel Service (UPS) presented a study to the American Society of Testing and Materials (ASTM) describing the conditions that packages experience in the single parcel shipping

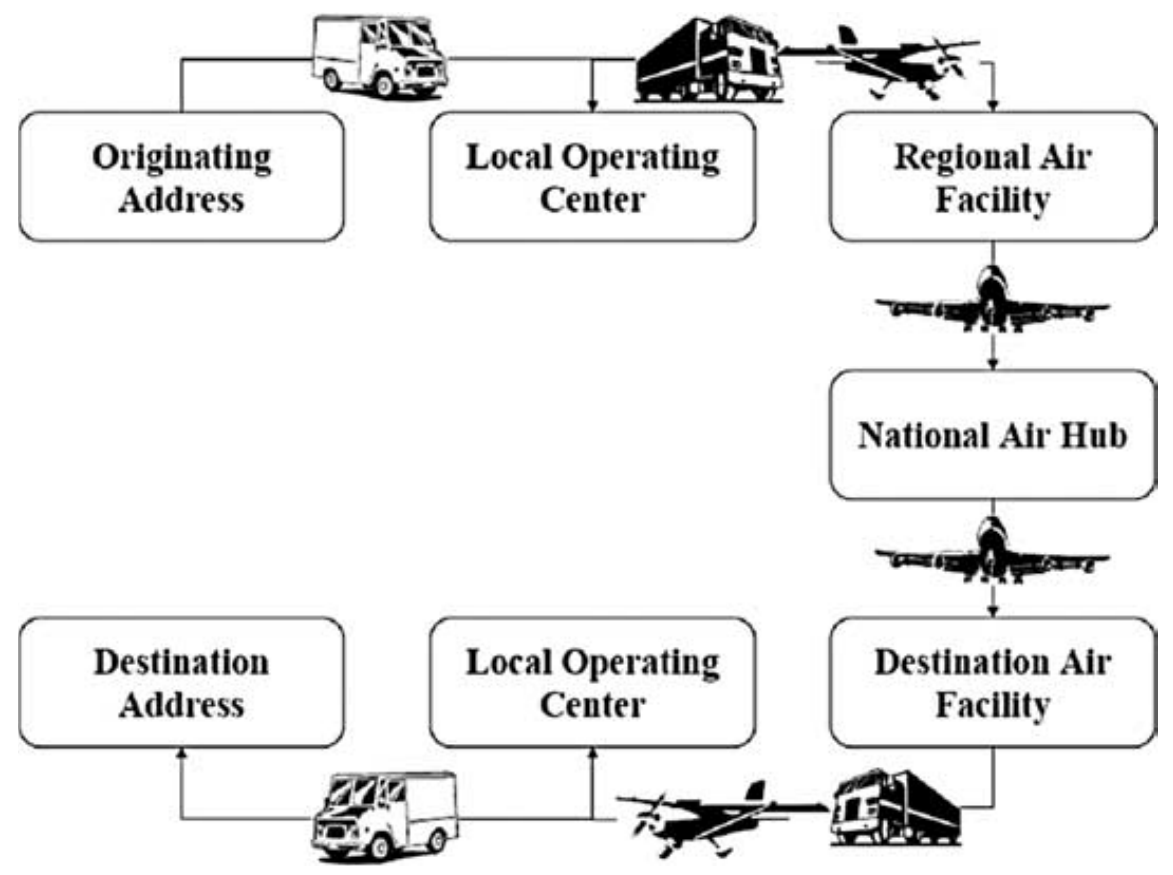

Figure 1. Typical package movement though FedEx express. 
environment. The study resulted in the following key observations as described in ASTM D6653-01: ${ }^{9}$

1. Cargo air jets are typically pressurized to about $75 \mathrm{kPa}$, which is normal atmospheric pressure at an altitude of $2438 \mathrm{~m}$. Temperature is maintained at approximately 20-23 ${ }^{\circ} \mathrm{C}$.

2. Packages transported on the ground may experience altitudes as high as $3658 \mathrm{~m}$ when shipped over certain mountain passes, especially in Colorado. Temperature extremes range from -15 to $30^{\circ} \mathrm{C}$ with average temperatures ranging from -4 to $18{ }^{\circ} \mathrm{C}$.

3. Non-pressurized 'feeder aircraft' typically fly at approximately $3963-4877 \mathrm{~m}$. The highest recorded altitude in a non-pressurized feeder aircraft was $6017 \mathrm{~m}$. Temperatures ranged from approximately -4 to $24{ }^{\circ} \mathrm{C}$.

ASTM D6653-01, Standard Test Methods for High Altitude on Packaging Systems by Vacuum Method, evaluates the effect of pressure differential when packaged products are transported by feeder aircrafts over high mountain passes. This test standard requires the following:

1. Conditioning and Testing
a. Conditioned and Tested at $5.60 \pm 2{ }^{\circ} \mathrm{C}$
i. Pressure equivalent to $4877 \mathrm{~m} \pm 5 \%$
b. Conditioned and Tested at $23 \pm 2^{\circ} \mathrm{C}$
i. Pressure equivalent to $4267 \mathrm{~m} \pm 5 \%$

2. Pressure Rise and Fall
a. $\quad 304.8 \mathrm{~m}$ every $30-60 \mathrm{~s}$
i. $\quad 4.06-10.2 \mathrm{~m} / \mathrm{s}$

3. Vacuum Time
a. $\quad 60 \mathrm{~min}$

The ASTM D6653-01 standard calls for test specimen to be conditioned at the temperature given in the first case for a minimum of $24 \mathrm{~h}$ prior to testing. ${ }^{9}$ The temperature given in the second case is recommended if the first condition is not possible. The standard calls for the test specimen to be tested at the pressure equivalent that corresponds to the conditioning condition.

This study had the following objectives:

1. Measure and analyze the environmental conditions in the FedEx Express' 'Priority Overnight' network;

2. Compare ASTM D6653-01 test procedure to environmental flight data from 'feeder' and 'pressurized' aircraft with respect to pressure, temperature, duration, and rise and fall time; and

3. Measure the environmental conditions of passenger aircrafts.

\section{EXPERIMENTAL DESIGN}

The goal of this study was to evaluate the single parcel environment of the 'Priority Overnight' service used by FedEx Express and commercial aircrafts. To accomplish the goals of this study, this experiment was designed to collect pressure and temperature data from both environments. The data collected describes the environment packaged products may experience. The instrumentation and packaging used will be described in this chapter

\section{Test Instrumentation and setup parameters}

Five MadgeTech PRTemp110 pressure and temperature recorders (Figure 2, MadgeTech, Inc., Contoocook, NH, USA) were acquired for this study and are referred to throughout this paper as data recorders. The data recorders can measure both temperature and pressure with respect to time. The 

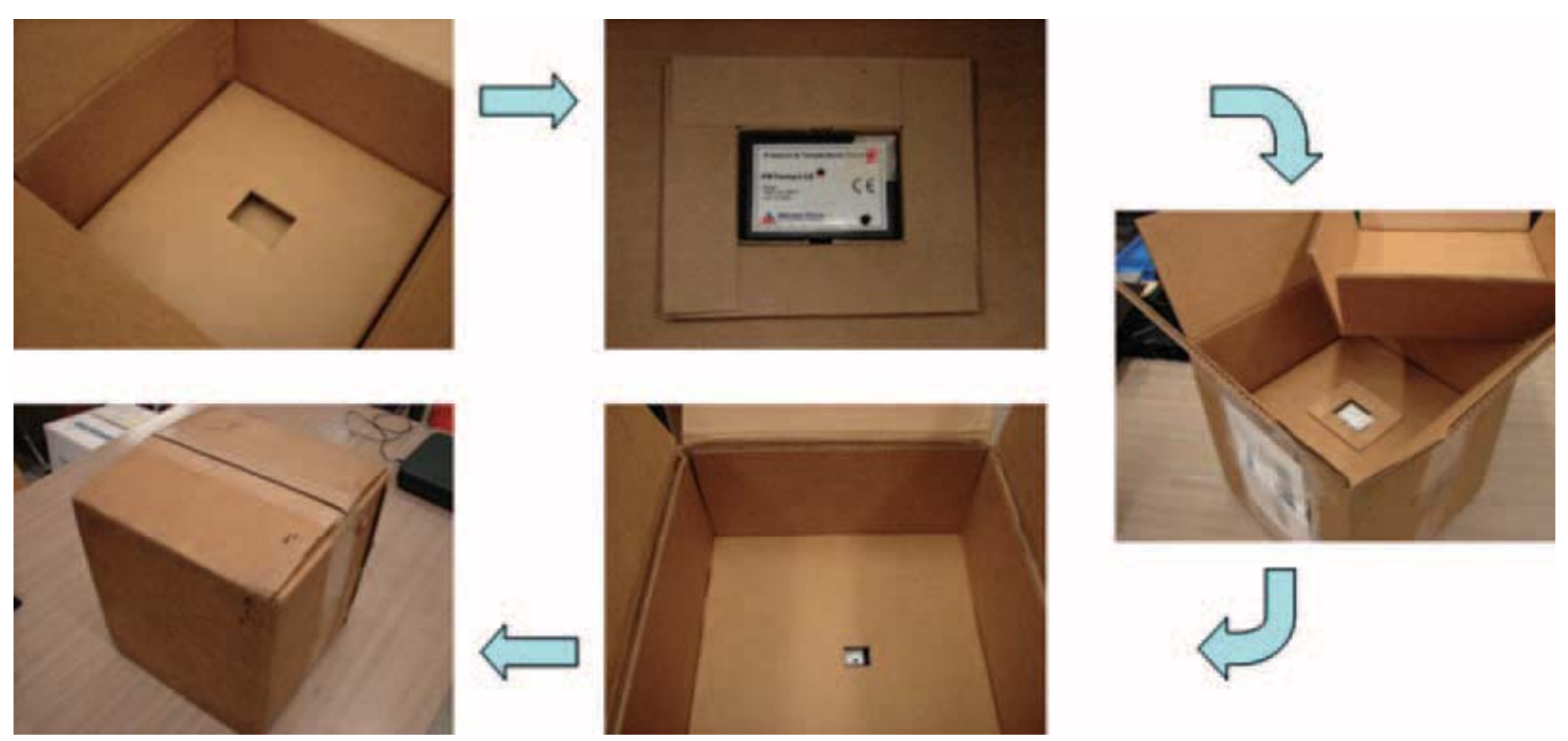

Figure 2. Single parcel test package setup. 
semiconductor temperature sensor can record temperatures from -40 to $80^{\circ} \mathrm{C}$ with a calibrated accuracy of $\pm 0.50{ }^{\circ} \mathrm{C}$ and a temperature resolution of $0.10^{\circ} \mathrm{C} .{ }^{10}$ The semiconductor (strain gauge) pressure sensor can record pressure data from 0 to $207 \mathrm{kPa}$ with a calibrated accuracy of $\pm 0.20 \%$ and a resolution of $0.014 \mathrm{kPa} .{ }^{10}$ The data recorder is able to record 16383 data points in each of its two channels in non-volatile solid state memory at sampling intervals from $2 \mathrm{~s}$ to $12 \mathrm{~h} .{ }^{10}$ The Data recorder's dimensions are $4.32 \times 5.84 \times 2.29 \mathrm{~cm}$ and it weighs $28.4 \mathrm{~g}$. Each data recorder is powered by a disposable 3.60 volt lithium battery.

The accompanying software was used to set up and download data from the data recorders. The software automatically calculates and stores calibration parameters and was also used to display and analyze the recorded data. The key configuration parameters include device interval and start delay.

The device interval controls the rate of temperature sample data. A smaller interval is necessary to measure and describe rise and fall rates and a larger interval is necessary to measure longer trips. The data recorder can be configured to record data at the following intervals of time:

$$
\begin{aligned}
& 2,5,10,15 \text { and } 30 \mathrm{~s} \\
& 1,5,10,15 \text { and } 30 \mathrm{~min} \\
& 1,2,4,8 \text { and } 12 \mathrm{~h}
\end{aligned}
$$

If environmental events are expected within a known window of time, the recorder can be setup to record data after a given value of time after configuration. This is known as a start delayed. Since each recorder's memory is limited, the start delay and the device interval settings are valuable setup parameters to record desired events.

\section{Test package system}

Test packages were used along with the data recorders to measure the pressure and temperature events the packages were exposed to in the FedEx Express and passenger aircraft environments.

When shipped through the FedEx Express network, the recorders were housed in the geometric centre of test packages made from double-wall corrugated board and paperboard. The test packages consisted of six components: one data recorder, one paperboard enclosure, three double-wall corrugated internal inserts, and the outer double-wall corrugated case. The three double-wall corrugated internal inserts were designed to hold the recorder/enclosure and to give additional internal bracing to provide strength. $6.45 \mathrm{sq} . \mathrm{cm}$ was cut into the top insert directly above the data recorder to provide a window for the pressure and temperature sensor. The outer double-wall corrugated case was a stapled regular slotted container. Figure 2 shows the test package assembly methodology. The size and weight of this test package were as follows:

Size: $0.30 \times 0.30 \times 0.30 \mathrm{~m}$

Test Package with data recorder weight: $1.42 \mathrm{~kg}$

When carried into the passenger cabin or checked with luggage on passenger aircrafts, the recorders were housed in a test packages made from single wall corrugated board. The test package was designed to protect the data recorder and provide convenience and portability. The test package consisted of six components: one data recorder, four corrugated internal inserts, and the corrugated case. The four corrugated internal inserts were designed to hold the recorder in place. $6.45 \mathrm{sq} . \mathrm{cm}$ was cut into the top insert directly above the data recorder to provide a window for the pressure and temperature sensor. The corrugated case was a one piece tuck in top. Figure 3 shows the passenger aircraft test package. The size and weight of this test package were as follows:

Size: $0.15 \times 0.11 \times 0.06 \mathrm{~m}$

Test Package with data recorder weight: $0.12 \mathrm{~kg}$

\section{Instrument setup parameters}

The software supplied with the data recorder permits communication between the user and the recorders. The software was used to configure and calibrate the recorders before shipment and to download 

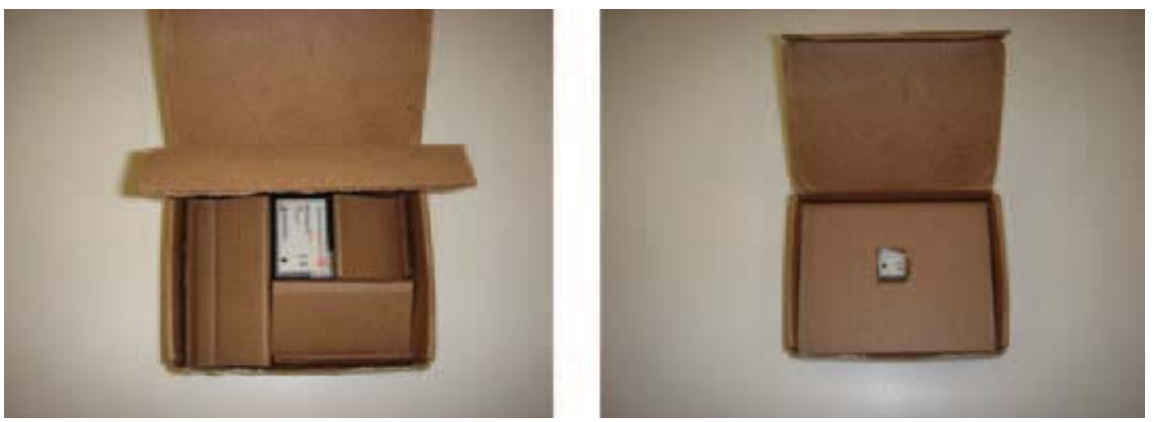

Figure 3. Data recorder in passenger test package.

data for analysis. The software was also used to display and analyze the recorded data. The key configuration parameters include start delay, and device interval. Details of the instrument setup parameters are provided in the Test Instrumentation and Setup Parameters section of this paper.

\section{Instrument configuration and calibration}

The recorders were calibrated by the manufacturer before being delivered for this experiment. To ensure the recorders functioned properly, simulated laboratory pressure tests were performed. The recorders were placed alone and in test packages into a pressure chamber to confirm the calibration parameters. This test was performed at the Michigan State University School of Packaging laboratory. A test was performed to determine the test package's effect on the recorded data. This test was also performed at the Michigan State University School of Packaging laboratory. Four data recorders were placed inside a vacuum chamber. Two recorders were placed inside a test package. The recorders collected pressure and temperature data every minute as the pressure inside the chamber changed (Figure 4). Table 1 show the temperature data collected. This data shows the temperature inside the test package is about $1.21^{\circ} \mathrm{C}$ warmer than the temperature outside the package. The pressure data collected by the recorders in the test packages was consistent with the pressure data collected by the recorders outside the test packages. The recorded pressure $(\mathrm{kPa})$ in the first column of the table reflects the gauge pressure plus barometric or atmospheric pressure.

\section{Data collection}

The intent of this study was to measure and analyze the pressure and temperature measured in feeder aircrafts in the single parcel environment. This data was to be compared to the pressure and temperatures measured on passenger aircrafts when carried on and checked with luggage.

To measure the single parcel environment, two destinations known to be served by non pressurized feeder aircrafts were identified to represent high altitude paths. The two destinations were San Luis Obispo, California and Twin Falls, Idaho. These were selected based on information obtained from FedEx representing the two highest altitude flight-paths using non-pressurized aircrafts. Replicate shipments were done in and out of these airports. The test packages were sent from East Lansing, Michigan. Multiple test packages were shipped to each destination to increase the reliability of the collected data and recorders were alternated though different destinations. For 6 weeks, two recorders were shipped to each destination. Test packages were shipped at the beginning of each week to ensure they were returned before the weekend.

The test packages were shipped Priority Overnight by FedEx Express. Test packages were picked up by FedEx Express from the School of Packaging at Michigan State University and loaded into a delivery vehicle. The packages were taken to the local FedEx operating station and consolidated with other packages intended for delivery.

When test packages were returned to East Lansing, the recorder's data was downloaded. Data was collected from three roundtrips and three one-way trips. During each trip, the test packages were passed through several distinguishable pressure events. On each trip, pressure events that exceed a 


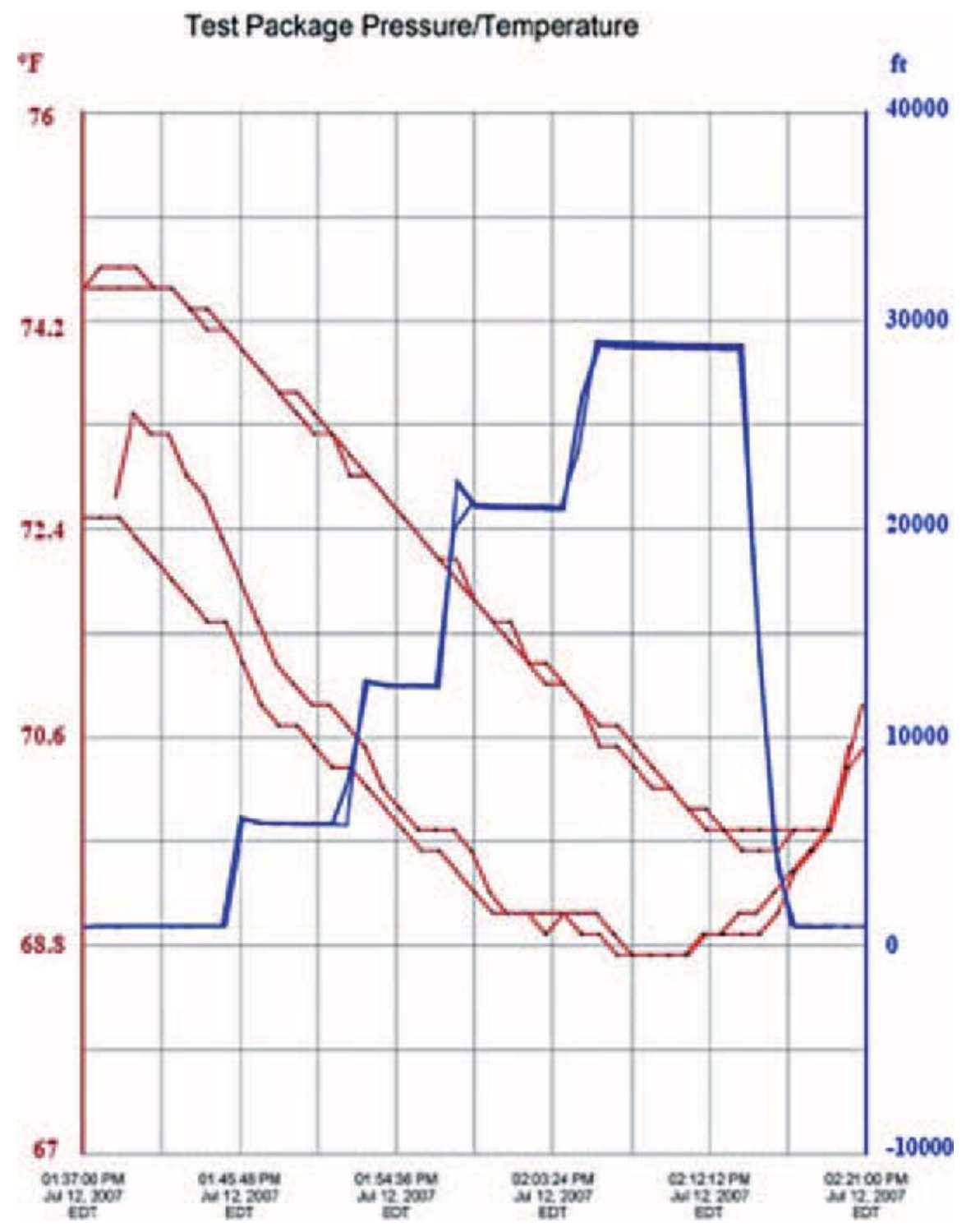

Figure 4. Recorded temperature and pressure of the test package.

Table 1. Average Temperature Difference Recorded.

\begin{tabular}{lccccc}
\hline & \multicolumn{2}{c}{$\begin{array}{c}\text { Recorders inside Test } \\
\text { Packages }\end{array}$} & & \multicolumn{2}{c}{$\begin{array}{c}\text { Recorders outside Test } \\
\text { Packages }\end{array}$} \\
\cline { 2 - 3 } \cline { 6 - 6 } & $1\left({ }^{\circ} \mathrm{C}\right)$ & $2\left({ }^{\circ} \mathrm{C}\right)$ & & $1\left({ }^{\circ} \mathrm{C}\right)$ & $2\left({ }^{\circ} \mathrm{C}\right)$ \\
\hline$\approx 97.9$ & 23.6 & 23.5 & & 22.3 & 22.7 \\
$\approx 80.7$ & 23.1 & 23.0 & & 21.5 & 21.7 \\
$\approx 62.7$ & 22.5 & 22.5 & & 21.0 & 21.0 \\
$\approx 44.1$ & 21.9 & 21.9 & & 20.6 & 20.6 \\
$\approx 31.7$ & 21.2 & 21.2 & & 20.4 & 20.5 \\
\hline
\end{tabular}

Average Difference $=1.21^{\circ} \mathrm{C}$.

pressure equivalent altitude of $2438 \mathrm{~m}$ were considered to be a feeder aircraft flight. The data was used to calculate the temperature range, maximum altitude and maximum altitude duration the package was exposed to during each event for each trip. Feeder aircraft data obtained from the one-way trips was also used to calculate the maximum altitude change during takeoffs and landings. Table 2 shows 
Table 2. Summary of FedEx Shipments

\begin{tabular}{cllllr}
\hline Shipment & Date & Origin & Destination & 1-Way/Return Trip & $\begin{array}{c}\text { Number of } \\
\text { Recorders }\end{array}$ \\
\hline 1 & $8 / 27 / 2007$ & East Lansing, MI & San Luis Obispo, CA & Return & 2 \\
2 & $9 / 4 / 2007$ & East Lansing, MI & San Luis Obispo, CA & Return & 2 \\
3 & $9 / 10 / 2007$ & East Lansing, MI & San Luis Obispo, CA & 1-Way & 1 \\
4 & $9 / 17 / 2007$ & East Lansing, MI & San Luis Obispo, CA & 1-Way & 2 \\
5 & $9 / 24 / 2007$ & East Lansing, MI & San Luis Obispo, CA & Return & 2 \\
6 & $10 / 1 / 2007$ & East Lansing, MI & San Luis Obispo, CA & 1-Way & 2 \\
7 & $8 / 27 / 2007$ & East Lansing, MI & Twin Falls, ID & Return & 2 \\
8 & $9 / 4 / 2007$ & East Lansing, MI & Twin Falls, ID & Return & 2 \\
9 & $9 / 10 / 2007$ & East Lansing, MI & Twin Falls, ID & $1-$ Way & 1 \\
10 & $9 / 17 / 2007$ & East Lansing, MI & Twin Falls, ID & 1-Way & 2 \\
11 & $9 / 24 / 2007$ & East Lansing, MI & Twin Falls, ID & Return & 2 \\
12 & $10 / 1 / 2007$ & East Lansing, MI & Twin Falls, ID & 1-Way & 2 \\
\hline
\end{tabular}

Table 3. Summary of Passenger Aircrafts Shipments

\begin{tabular}{lllll}
\hline Shipment & Date & Origin & Destination & Via \\
\hline 1 & $7 / 27 / 2007$ & East Lansing, MI & Sacramento, CA & Minneapolis, MS \\
2 & $8 / 1 / 2007$ & East Lansing, MI & AR & None \\
3 & $8 / 6 / 2007$ & East Lansing, MI & Bangkok, Thailand & Detroit, MI; Tokyo, Japan \\
\hline
\end{tabular}

this test history. It should be noted that the original reference study that was the basis of ASTM D6653-01, done by UPS, has never been accessible either from UPS or ASTM, and hence, the premise for conducting this study.

Data was also collected to measure the environment of commercial aircrafts. In July 2007, the test package designed for passenger aircrafts was carried on two connecting flights, Michigan to Minneapolis and Minneapolis to California, and on return, checked with luggage. (Boeing DC-9 and Airbus A320) In August 2007, the test package was checked on a one-way regional Jet from Michigan to Arkansas. Later in August 2007, the test package was checked to measure the environment of connecting flights in a one-way international trip from Michigan to Bangladesh. Table 3 shows this test history.

\section{DATA AND RESULTS}

The data acquired from the recorders was downloaded using the MadgeTech Data Recorder Software. The software was used to convert the pressure data into its altitude equivalent using the International Standard Atmosphere model. The data was exported into spreadsheets for analysis. Table 4 shows altitude and pressure conversion data.

Tables 5 and 6 show the maximum pressure equivalent measured for each pressure event in all one-way and round-trip shipment as well as the time it was observed within $183 \mathrm{~m}$ in the FedEx Express environment. Tables 7 and 8 show the maximum and minimum temperature measured for each pressure event in all one-way and round-trip shipment in the FedEx Express environment. Table 6 also shows the greatest altitude change in an observed five second interval during the aircraft's take off and landing for the event with the greatest altitude. These events are assumed to represent a FedEx Express feeder aircraft. Figure 5 shows graphed round-trip pressure data recorded on the August 27th trip. The altitude peaks greater than $2438 \mathrm{~m}$ represent a feeder aircraft and are identified.

Table 9 shows the maximum pressure equivalent altitude, maximum temperature, and minimum temperature measured for each passenger flight trip studied. 
Table 4. Altitude/Pressure Table.

\begin{tabular}{cccc}
\hline Altitude, $\mathrm{ft}$ & Altitude, $\mathrm{m}$ & Pressure, inHg & Pressure, $\mathrm{kPa}$ \\
\hline 0 & 0 & 29.9 & 101.3 \\
1000 & 305 & 28.9 & 97.7 \\
5000 & 1524 & 24.9 & 84.3 \\
8000 & 2438 & 22.2 & 75.3 \\
10000 & 3048 & 20.6 & 69.7 \\
12000 & 3658 & 19.1 & 64.5 \\
14000 & 4267 & 17.6 & 59.5 \\
16000 & 4877 & 16.2 & 54.9 \\
18000 & 5486 & 14.9 & 50.6 \\
20000 & 6096 & 13.8 & 46.6 \\
26000 & 7925 & 10.6 & 36.0 \\
30000 & 9144 & 8.9 & 30.1 \\
40000 & 12192 & 5.5 & 18.8 \\
50000 & 15240 & 3.4 & 11.6 \\
\hline
\end{tabular}

Table 5. Summary of Altitude Round Trip.

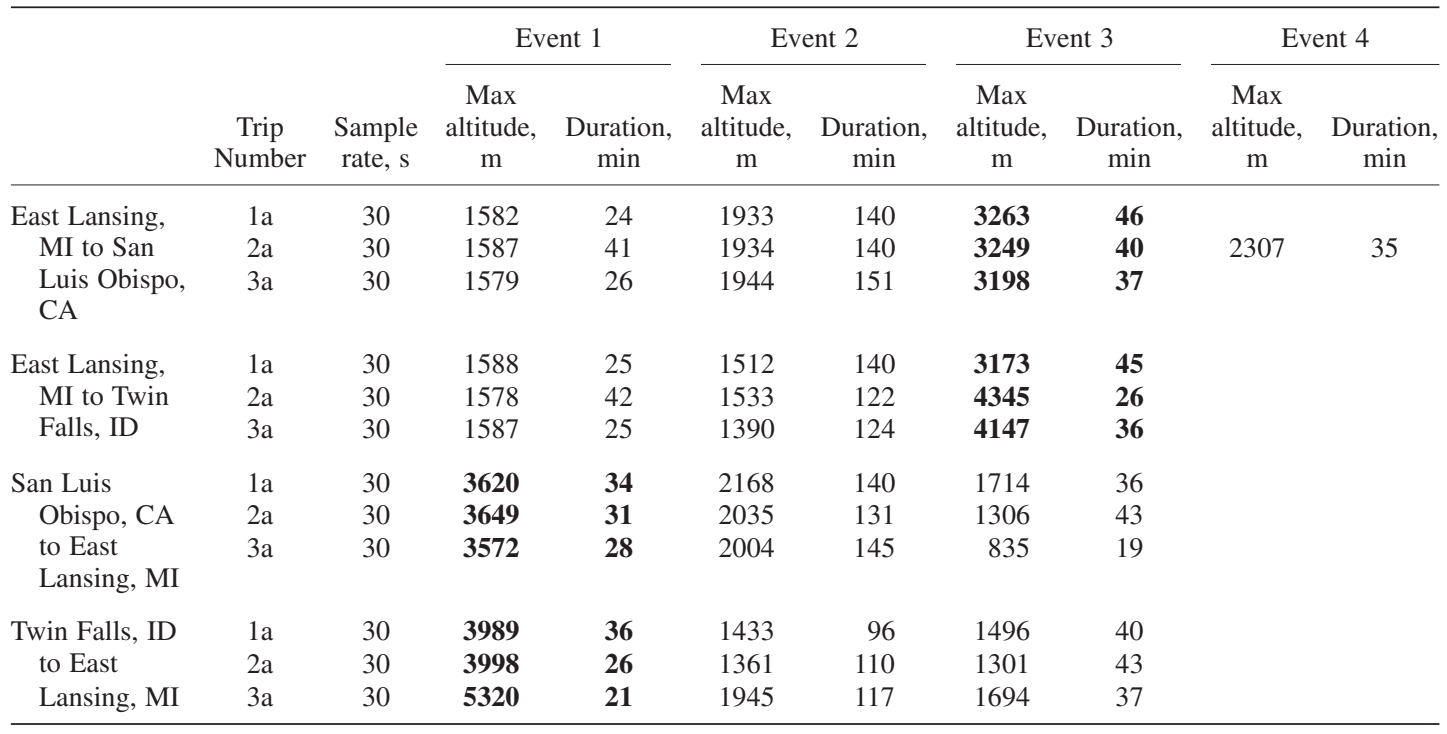

Note: Bold events represent a feeder aircraft.

Table 6. Summary of Altitude One-Way Trip.

\begin{tabular}{|c|c|c|c|c|c|c|c|c|c|c|}
\hline & \multirow[b]{2}{*}{$\begin{array}{c}\text { Trip } \\
\text { Number }\end{array}$} & \multirow[b]{2}{*}{$\begin{array}{c}\text { Sample } \\
\text { rate, s }\end{array}$} & \multicolumn{2}{|c|}{ Event 1} & \multicolumn{2}{|c|}{ Event 2} & \multicolumn{2}{|c|}{ Event 3} & \multirow[b]{2}{*}{$\begin{array}{l}\text { Max } \\
\text { rise } \\
\mathrm{m} / \mathrm{s}\end{array}$} & \multirow[b]{2}{*}{$\begin{array}{r}\text { Max } \\
\text { fall } \\
\mathrm{m} / \mathrm{s}\end{array}$} \\
\hline & & & $\begin{array}{c}\text { Max } \\
\text { altitude, } \\
\text { m }\end{array}$ & $\begin{array}{l}\text { Duration, } \\
\text { min }\end{array}$ & $\begin{array}{c}\text { Max } \\
\text { altitude, } \\
\mathrm{m}\end{array}$ & $\begin{array}{c}\text { Duration, } \\
\text { min }\end{array}$ & $\begin{array}{c}\text { Max } \\
\text { altitude, } \\
\mathrm{m}\end{array}$ & $\begin{array}{l}\text { Duration, } \\
\text { min }\end{array}$ & & \\
\hline \multirow{3}{*}{$\begin{array}{l}\text { East Lansing, } \\
\text { MI to San } \\
\text { Luis Obispo, } \\
\text { CA }\end{array}$} & $1 \mathrm{a}$ & 5 & 1599 & 28 & 2093 & 160 & 2616 & 45 & 5.03 & 7.32 \\
\hline & $2 \mathrm{a}$ & 5 & 1576 & 29 & 2105 & 156 & 3192 & 37 & 5.26 & 7.45 \\
\hline & $3 a$ & 5 & 1607 & 25 & 1921 & 166 & 3164 & 34 & 5.78 & 8.43 \\
\hline \multirow{4}{*}{$\begin{array}{c}\text { East Lansing, } \\
\text { MI to Twin } \\
\text { Falls, ID }\end{array}$} & $1 \mathrm{a}$ & 5 & 1593 & 28 & 1678 & 115 & 3679 & 21 & 5.00 & 6.60 \\
\hline & $2 a$ & 5 & 1569 & 29 & 1449 & 115 & 3925 & 35 & 6.04 & 6.40 \\
\hline & $3 a$ & 5 & 1603 & 25 & 1506 & 129 & 4159 & 42 & 5.61 & 6.64 \\
\hline & & & & & & & & Max & 6.04 & 8.43 \\
\hline
\end{tabular}

Note: Bold events represent a feeder aircraft. 
Table 7. Summary of Temperature Round Trip.

\begin{tabular}{|c|c|c|c|c|c|c|c|c|c|c|}
\hline & \multirow[b]{2}{*}{$\begin{array}{c}\text { Trip } \\
\text { Number }\end{array}$} & \multirow[b]{2}{*}{$\begin{array}{l}\text { Sample } \\
\text { interval, } \\
\text { s }\end{array}$} & \multicolumn{2}{|c|}{ Event 1} & \multicolumn{2}{|c|}{ Event 2} & \multicolumn{2}{|c|}{ Event 3} & \multicolumn{2}{|c|}{ Event 4} \\
\hline & & & $\begin{array}{l}\text { Max } \\
\text { temp., } \\
{ }^{\circ} \mathrm{C}\end{array}$ & $\begin{array}{l}\text { Min } \\
\text { temp., } \\
{ }^{\circ} \mathrm{C}\end{array}$ & $\begin{array}{l}\text { Max } \\
\text { temp., } \\
{ }^{\circ} \mathrm{C}\end{array}$ & $\begin{array}{l}\text { Min } \\
\text { temp., } \\
{ }^{\circ} \mathrm{C}\end{array}$ & $\begin{array}{l}\text { Max } \\
\text { temp., } \\
{ }^{\circ} \mathrm{C}\end{array}$ & $\begin{array}{l}\text { Min } \\
\text { temp., } \\
{ }^{\circ} \mathrm{C}\end{array}$ & $\begin{array}{c}\text { Max } \\
\text { temp., } \\
{ }^{\circ} \mathrm{C}\end{array}$ & $\begin{array}{l}\text { Min } \\
\text { temp., } \\
{ }^{\circ} \mathrm{C}\end{array}$ \\
\hline \multirow{2}{*}{$\begin{array}{l}\text { East Lansing, MI to } \\
\text { San Luis Obispo, } \\
\text { CA }\end{array}$} & $1 \mathrm{a}$ & 30 & 21.0 & 20.4 & 26.7 & 21.1 & 24.9 & 7.8 & \multirow[b]{2}{*}{20.0} & \multirow[b]{2}{*}{19.2} \\
\hline & $2 a$ & 30 & 26.4 & 21.2 & 26.0 & 21.9 & 21.7 & 20.1 & & \\
\hline \multirow{3}{*}{$\begin{array}{l}\text { East Lansing, MI to } \\
\text { Twin Falls, ID }\end{array}$} & $1 \mathrm{a}$ & 30 & 25.7 & 17.1 & 19.2 & 17.0 & 25.1 & 22.8 & & \\
\hline & $2 a$ & 30 & 26.5 & 22.5 & 24.7 & 23.4 & 19.6 & 13.3 & & \\
\hline & $3 a$ & 30 & 25.4 & 24.1 & 26.3 & 23.2 & 12.7 & 10.2 & & \\
\hline $\begin{array}{l}\text { San Luis Obispo, CA } \\
\text { to East Lansing, } \\
\text { MI }\end{array}$ & $1 \mathrm{a}$ & 30 & 26.6 & 21.6 & 28.6 & 25.4 & 28.0 & 24.3 & & \\
\hline \multirow{2}{*}{$\begin{array}{l}\text { Twin Falls, ID to } \\
\text { East Lansing, MI }\end{array}$} & $2 a$ & 30 & 25.7 & 17.1 & 19.2 & 16.8 & 25.1 & 22.8 & & \\
\hline & $3 a$ & 30 & 23.9 & 15.7 & 14.7 & 11.5 & 24.7 & 22.0 & & \\
\hline
\end{tabular}

Table 8. Summary of Temperature One-Way Trip.

\begin{tabular}{|c|c|c|c|c|c|c|c|c|}
\hline & \multirow[b]{2}{*}{$\begin{array}{l}\text { Trip } \\
\text { Number }\end{array}$} & \multirow[b]{2}{*}{$\begin{array}{c}\text { Sample } \\
\text { interval, } \\
\mathrm{s}\end{array}$} & \multicolumn{2}{|c|}{ Event 1} & \multicolumn{2}{|c|}{ Event 2} & \multicolumn{2}{|c|}{ Event 3} \\
\hline & & & $\begin{array}{c}\text { Max } \\
\text { temp., } \\
{ }^{\circ} \mathrm{C}\end{array}$ & $\begin{array}{l}\text { Min } \\
\text { temp., } \\
{ }^{\circ} \mathrm{C}\end{array}$ & $\begin{array}{c}\text { Max } \\
\text { temp., } \\
{ }^{\circ} \mathrm{C}\end{array}$ & $\begin{array}{l}\text { Min } \\
\text { temp., } \\
{ }^{\circ} \mathrm{C}\end{array}$ & $\begin{array}{c}\text { Max } \\
\text { temp., } \\
{ }^{\circ} \mathrm{C}\end{array}$ & $\begin{array}{c}\text { Min } \\
\text { temp., } \\
{ }^{\circ} \mathrm{C}\end{array}$ \\
\hline \multirow{2}{*}{$\begin{array}{l}\text { East Lansing, MI to San } \\
\text { Luis Obispo, CA }\end{array}$} & $1 \mathrm{a}$ & 5 & 22.4 & 20.1 & 24.9 & 22.0 & 21.0 & 18.6 \\
\hline & $2 a$ & 5 & 16.6 & 16.4 & 23.7 & 21.4 & 25.6 & 16.5 \\
\hline \multirow{3}{*}{$\begin{array}{l}\text { East Lansing, MI to Twin } \\
\text { Falls, ID }\end{array}$} & $1 \mathrm{a}$ & 5 & 25.1 & 20.8 & 26.3 & 25.0 & 19.1 & 14.5 \\
\hline & $2 \mathrm{a}$ & 5 & 18.5 & 18.4 & 25.1 & 20.6 & 17.4 & 15.2 \\
\hline & $3 a$ & 5 & 17.2 & 17.0 & 22.9 & 22.2 & 13.8 & 12.0 \\
\hline
\end{tabular}

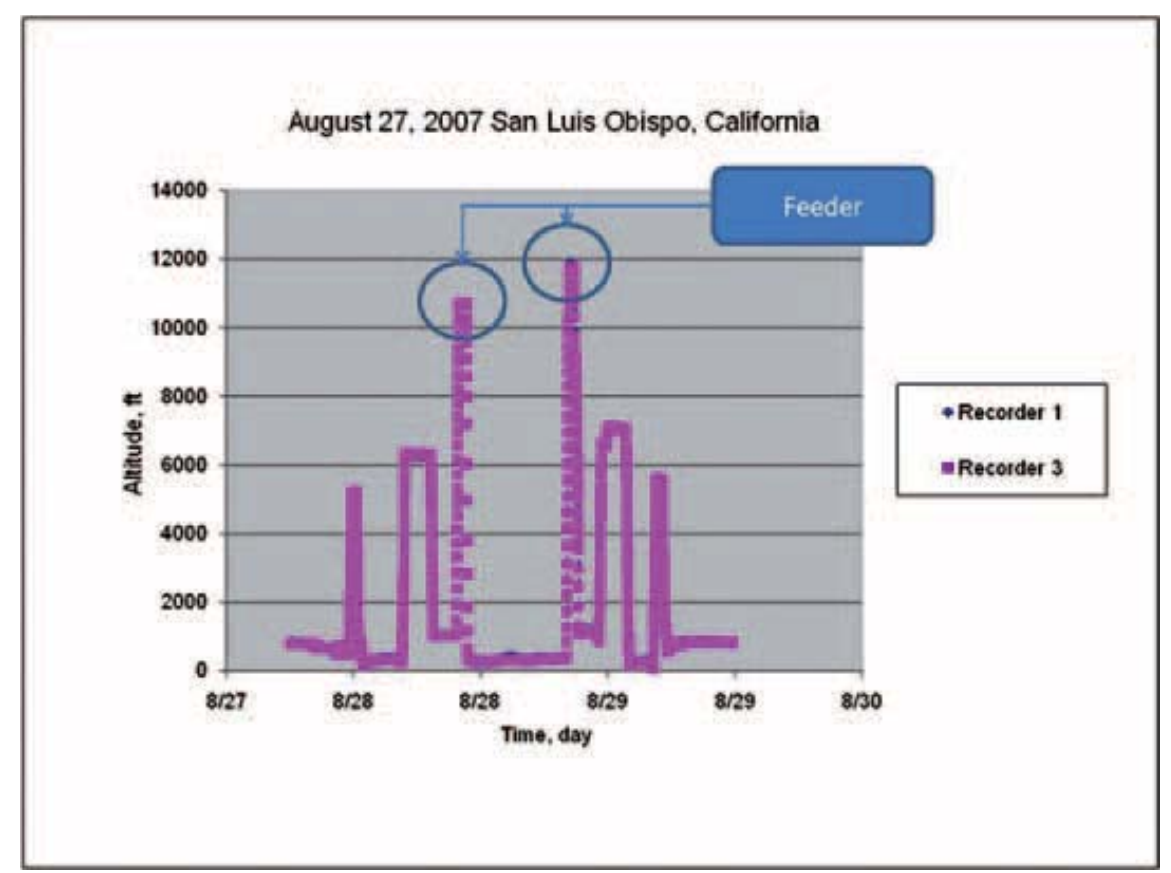

Figure 5. San Luis Obispo round trip altitude data, August 27. 
Table 9. Summary of Passenger Flights.

\begin{tabular}{llllcrr}
\hline Date & Description & Sample & & Max \\
rate & Cabin/checked & $\begin{array}{c}\text { Max } \\
\text { altitude, } \\
\mathrm{m}\end{array}$ & $\begin{array}{c}\text { temp., } \\
{ }^{\circ} \mathrm{C}\end{array}$ & $\begin{array}{c}\text { Min } \\
\text { temp., } \\
{ }^{\circ} \mathrm{C}\end{array}$ \\
\hline $7 / 27 / 2007$ & Michigan-Minnesota-California & $5 \mathrm{~min}$ & Checked & 2186 & 26.0 & 13.9 \\
$7 / 29 / 2007$ & California-Minnesota-Michigan & $5 \mathrm{~min}$ & Cabin & 2247 & 25.8 & 22.2 \\
$8 / 1 / 2007$ & Michigan-Arkansas & $10 \mathrm{~s}$ & Checked & 1359 & 26.0 & 25.0 \\
$8 / 6 / 2007$ & Michigan-Michigan & $30 \mathrm{~s}$ & Checked & 1934 & 24.9 & 22.7 \\
- & Michigan-Tokyo, Japan & $30 \mathrm{~s}$ & Checked & 1782 & 24.8 & 17.3 \\
- & Tokyo, Japan-Bangladesh & $30 \mathrm{~s}$ & Checked & 2137 & 22.6 & 21.0 \\
\hline
\end{tabular}

\section{CONCLUSIONS}

The study concludes the following:

1. The highest pressure equivalent altitude observed in the FedEx environment for six round trips and five one-way trips from East Lansing, Michigan to San Luis Obispo, California was $3649 \mathrm{~m}$ with a temperature of $21.4-26.9^{\circ} \mathrm{C}$.

2. The highest pressure equivalent altitude observed in the FedEx environment for six round trips and five one-way trips from East Lansing, Michigan to Twin Falls, Idaho was $5320 \mathrm{~m}$ with a temperature of $15.7-23.9^{\circ} \mathrm{C}$.

3. The existing ASTM D6653-01 test procedure, Standard Test Methods for Determining the Effects of High Altitude on Packaging Systems by Vacuum Method, suggests a pressure equivalent to $14000 \mathrm{ft}$ when conditioned and tested at $23 \pm 2^{\circ} \mathrm{C}$, or $4877 \mathrm{~m}$ when conditioned and tested at $5.6 \pm 2{ }^{\circ} \mathrm{C}$. The highest pressure equivalent altitude observed in the FedEx environment of $5320 \mathrm{~m}$ and $15.7-23.9^{\circ} \mathrm{C}$ is more strenuous.

4. The largest feeder flight duration observed in the FedEx environment was approximately $46 \mathrm{~min}$. The existing ASTM D6653-01 test procedure suggests a vacuum be maintained for $60 \mathrm{~min}$. The maximum pressure equivalent altitude measured during this shipment was $3263 \mathrm{~m}$.

5. The largest flight duration observed in the FedEx environment was approximately $166 \mathrm{~min}$.

6. The existing ASTM D6653-01 test procedure, Standard Test Methods for Determining the Effects of High Altitude on Packaging Systems by Vacuum Method, suggests that test chamber vacuum should be raised at a rate of $306 \mathrm{~m}$ every $30-60 \mathrm{~s}(4.10-10.2 \mathrm{~m} / \mathrm{s})$. All maximum rise and fall changes observed in the FedEx environment fell within this range. This is consistent with known aviation practices and limitations.

7. The pressure measured in the cabin of passenger aircrafts was not significantly different than the pressure measured in the cargo hold.

\section{ACKNOWLEDGEMENTS}

The authors would like to thank the Consortium of Distribution Packaging Research for providing funding for this project. In addition we appreciate the guidance from Ms. Janet McLaughlin of the Federal Aviation Administration and Mr. Tom Wood of FedEx during this project.

\section{REFERENCES}

1. Singh SP, Burgess GJ, Singh J. Package performance testing of dangerous goods in high altitude shipments. Packaging Technology and Science 2003; 16: 119-130.

2. Wybenga F. Air transport incident data and analysis of packaging failures. Dangerous Goods Panel Meeting Proceedings, Singapore, 14-18 May, 2001. 
3. Singh SP, McLaughlin J. Package testing for real world conditions. Dangerous Goods by Air 2004 Proceedings, International Air Transport Association, Prague, Czech Republic, 2004.

4. Singh SP, Burgess G, Singh J. A new test method and pictorial markings for packages containing liquid dangerous goods in high altitude shipments. Journal of Testing and Evaluation 2004; 32(5): 417-420.

5. Singh SP, Singh J. Pictorial markings and labels for safe shipment and handling of packaged goods. Packaging Technology and Science 2005; 18: 133-140.

6. Singh SP, Burgess G, Singh J, Lockhart H. High altitude testing and evaluation of liquid pharmaceutical glass and plastic bottles to detect leaks. Journal of ASTM International 2007; 4(3): DOI: 10.1520/JAI100742.

7. FedEx Express. FedEx express fact sheet. FedEx Express, 2007.

8. FedEx Corporation, FedEx Corporation fact sheet. FedEx Corporation, 2007

9. ASTM D 6653-01. Standard test methods for determining the effects of high altitude on packaging systems by vacuum method. Annual Book of ASTM Standards, Vol. 15.10 ASTM International, West Conshohocken, PA, 2005; 682-685.

10. MadgeTech PRTemp110, Product Information Card, http://www.madgetech.com/pdf_files/productreferencecards/ PRTemp101_110_Reference_card.pdf [accessed 3 May 2009]. 